\title{
Development of Energy Balance of Light Weight Electric Vehicle in Motion for Energy Conservation
}

\author{
Shivraj Pawar ${ }^{1}$, M. M. Wagh ${ }^{2}$, N. N. Shinde ${ }^{3}$ \\ ${ }^{1}$ Energy Technology, Department of Technology, Shivaji University Kolhapur \\ ${ }^{2,3}$ Professor, Energy Technology, Department of Technology, Shivaji University Kolhapur
}

\begin{abstract}
In forthcoming years, total fuel demand in all transport modes will increase. Fuel demand for the Light Duty Vehicles in the transport market, is expected to increase further. In addition, the transportation sector will still depend heavily on gasoline, diesel, and jet fuel, since they all create the majority of transport market fuels. Thus it is essential to study the conservation of energy in light duty vehicles in transportation sector. The result of parameters - air resistance, rolling resistance and mass of vehicle is premeditated for Indian urban and highway driving cycle. The power usage is calculated separately. The simulation tool used is ADVISOR.
\end{abstract}

Keywords: electric vehicle, energy balance, rolling resistance, air resistance, Advisor

\section{Introduction}

In case of electric vehicles energy balance based on electric energy used. This energy is used to overcoming the forces acting on the vehicle in the opposite direction of the motion. The modelling of energy balance is done in view of the fundamental parameters that take part in forming the forces like drag, friction etc. while work is being done by the vehicle.[18]

The vehicle considered for this work is light weight electrical vehicle i.e. vehicle having maximum gross vehicle weight rating $<8500 \mathrm{lbs}$ as per standards.

\section{Factors affecting the energy balance}

The dynamic equations of the vehicle are used to analyse the impact of drive cycle on the performance .These equations provide the force requisite to move vehicle and this force is given by

$F_{\text {resistance }}=F_{Y}+F_{W}+F_{g}+F_{a}$

$F_{\text {resistance }}=M g f_{Y} \cos \alpha+\frac{1}{2} \rho A_{f} C_{D} V^{2}+M g \sin \alpha+\delta M \frac{d V}{d T}$

The power can be determined as

$P_{\text {resiatance }}=P_{Y}+P_{W}+P_{g}+P_{a}$

Where,

$P_{Y}=F_{\gamma} V_{s} P_{W}=F_{W} V_{s} P_{g}=F_{g} V_{s} P_{a}=F_{a} V$

Therefore above equation can be transformed as

$P_{\text {resistance }}=$

$\mathrm{V}\left\{M g f_{r} \cos \alpha+\frac{1}{2} \rho A_{f} C_{D} V^{2}+M g \sin \alpha+\delta M \frac{d V}{d T}\right\}$

This is called the power equation as it is written in terms of fundamental design parameters like speed of the vehicle, mass of the vehicle, coefficient of air and rolling resistance. In practice the total energy generated by the energy storage is used for above basic resistances plus auxiliary consumptions like lighting, space conditioning, automation equipments and devices.
Each utilization has its own conversation efficiencies called losses. The energy conservation can be achieved by improving efficiencies or reducing the losses.[18]

Considering all these losses the energy utilized can be calculated. The energy balance at steady state, thus can be written as under power requirements of the vehicle with the various loss.

It is represented as in figure 1.

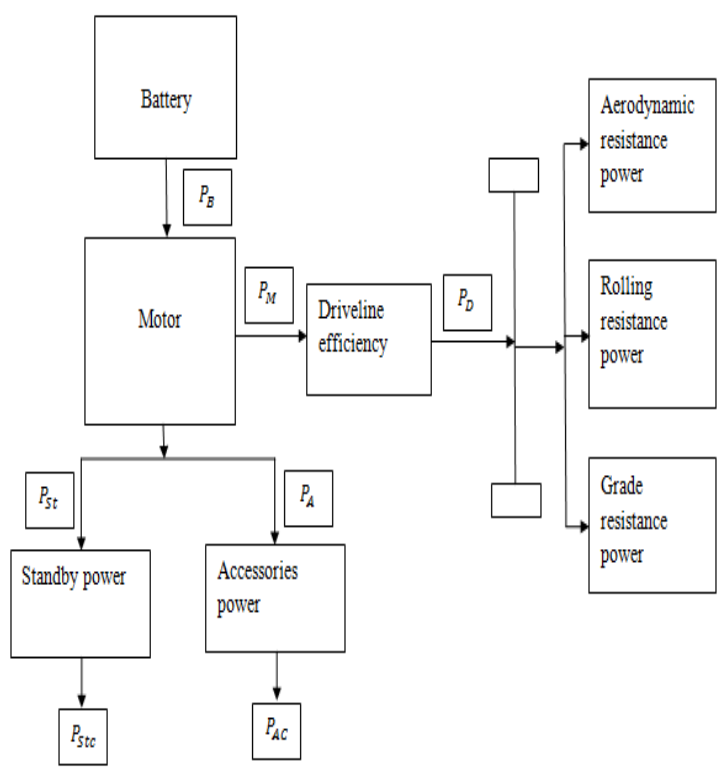

Fig.1 Energy flows for electric vehicle

$$
\begin{aligned}
& P_{\text {in }}=\left(\frac{P_{\text {ste }}}{\eta_{M} \eta_{s t}}+\frac{P_{A c}}{\eta_{M} \eta_{A}}+\frac{1}{\eta_{M} \eta_{D}}\left[V\left\{M g f_{g} \cos \alpha+\frac{1}{2} \rho A_{f} C_{D} V^{2}+M g \sin a+\delta M \frac{d V}{d T}\right\}\right]\right) \\
& P_{\text {in }}=\left(\frac{1}{\eta_{M} \eta_{\text {st }}} P_{\text {ste }}+\frac{1}{\eta_{M} \eta_{A}} P_{A c}+\frac{1}{\eta_{M} \eta_{D}}\left[V\left\{M g f_{y} \cos a+\frac{1}{2} \rho A_{f} C_{D} V^{2}+M g \sin a+\delta M \frac{d V}{d T}\right\}\right)\right.
\end{aligned}
$$




$$
P_{\mathrm{in}}=\left(K_{E V 1} P_{S t e}+K_{E V 2} P_{A e}+K_{E V /}\left[V\left\{M g f_{f} \cos a+\frac{1}{2} \rho A_{f} C_{D} V^{2}+M g \sin a+\delta M \frac{d V}{d T}\right\}\right]\right)
$$

Where

$$
\begin{aligned}
& P_{A}=\text { Power consumed in accessories } \\
& \eta_{A}=\text { efficiency of accesories } \\
& \eta_{M}=\text { Motor efficiency } \\
& P_{S t}=\text { Standby power } \\
& \eta_{s t}=\text { standby efficiency } \\
& P_{D}=\text { power to driveline } \\
& \eta_{D}=\text { driveline efficiency } \\
& P_{W}=\text { power available at wheels } \\
& K_{E V 1} K_{E v 2} K_{E v a}=\text { dimensionless costant } \\
& K_{E V 1}=\frac{1}{\eta_{M} \eta_{S t}} \\
& K_{E v 2}=\frac{1}{\eta_{M} \eta_{A}} \\
& K_{E v a}=\frac{1}{\eta_{M} \eta_{D}}
\end{aligned}
$$

$K_{E V 1}, K_{E V 2}, K_{E V a}=$ dimensionless costant

As these constants can be found out for different vehicle types the availability of the power can be determined using these equations as per the urban and highway conditions.

\section{Use of ADVISOR to Calculating Power Over Drive Cycle}

There are several computer software simulations existing specifically for vehicles. These simulation tools have varying abilities to predict vehicle performance in one or more areas, such as fuel economy, emissions, acceleration, and grade sustainability such as CarSim, VElph, SIMPLEV, HVEC and ADVISOR. The ADVISOR is acronym of The Advanced Vehicle Simulator. It is developed by the National Renewable Energy Laboratory. It is the latest of the hybrid and electric vehicle simulation tools. It consists of various features and simplicity which is necessary for the testing of variety of vehicles.

As with many of the simulations mentioned previously, ADVISOR can utilize a variety of custom and standard driving cycles. Nevertheless, contrasting any of the other tools, it also easily generates results from batches of cycles.

ADVISOR can be used for the study and prediction of various drive cycles. It also calculates the fuel economy, emissions, acceleration, and grade ability of a given vehicle and plot results based on models.

In this work ADVISOR run through MATLAB to determine the operating conditions for electric vehicle configuration for Indian highway and Indian urban cycle. The electric vehicle with mass $1100 \mathrm{~kg}$ is selected with drag coefficient varying as 0.335 to 0.65 and for frontal area 2 sq. m. The model is selected as below which includes battery i.e. energy storage, motor/controller and driveline. The other operating conditions are as per Indian driving cycle sample.

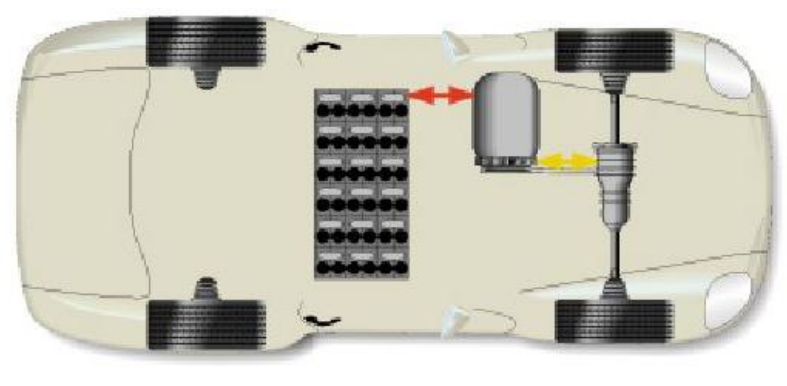

Figure 2: Model of electric vehicle in ADVISOR

The Indian highway and Indian urban driving cycle are as shown below.

The Indian highway driving cycle consists of idle time as 3 sec over a period. The drive cycle is plotted as the speed in $\mathrm{mph}$ on the $\mathrm{y}$ axis and time of the cycle is on the $\mathrm{x}$ axis.

The Indian urban drive cycle considers $881 \mathrm{sec}$ to complete the trip of the vehicle. The variations in the speed are due to the propelling that is accelerating and braking and at idle time.

For highway cycle the parameters are chosen from the values of different speeds for following conditions:

Time: $881 \mathrm{~s}$

Distance: $11.65 \mathrm{~km}$

Max. Speed: $76 \mathrm{kmph}$

Avg. speed: $47.5 \mathrm{kmph}$

Max. Acceleration: $2.12 \mathrm{~m} / \mathrm{s} 2$

Max. Deceleration: $-1.99 \mathrm{~m} / \mathrm{s} 2$

Avg. acceleration: $0.32 \mathrm{~m} / \mathrm{s} 2$

Avg. deceleration: $-0.39 \mathrm{~m} / \mathrm{s} 2$

Idle time: $3 \mathrm{~s}$

The Indian urban driving cycle consists of idle time as 267 sec over a period. The drive cycle is plotted as the speed in mph on the $y$ axis and time of the cycle is on the $\mathrm{x}$ axis.

The Indian urban drive cycle considers $2689 \mathrm{sec}$ to complete the trip of the vehicle. The variations in the speed are due to the propelling that is accelerating and braking and at idle time.

For urban conditions the operating conditions are as below:

Time: $2689 \mathrm{~s}$

Distance: $17.5 \mathrm{~km}$

Max. speed: $62.5 \mathrm{kmph}$

Avg. speed: $23.39 \mathrm{kmph}$

Max. Acceleration: $1.73 \mathrm{~m} / \mathrm{s}^{2}$

Max. Deceleration: $-2.10 \mathrm{~m} / \mathrm{s}^{2}$

Avg. acceleration: $0.32 \mathrm{~m} / \mathrm{s}^{2}$

Avg. deceleration: $0.39 \mathrm{~m} / \mathrm{s}^{2}$

Idle time: $267 \mathrm{~s}$ 


\section{International Journal of Science and Research (IJSR) \\ ISSN (Online): 2319-7064}

Index Copernicus Value (2013): 6.14 | Impact Factor (2014): 5.611

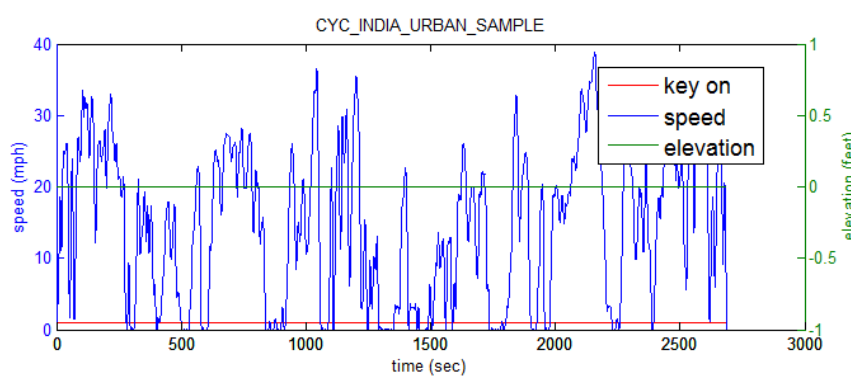

Graph 1: Indian urban drive cycle

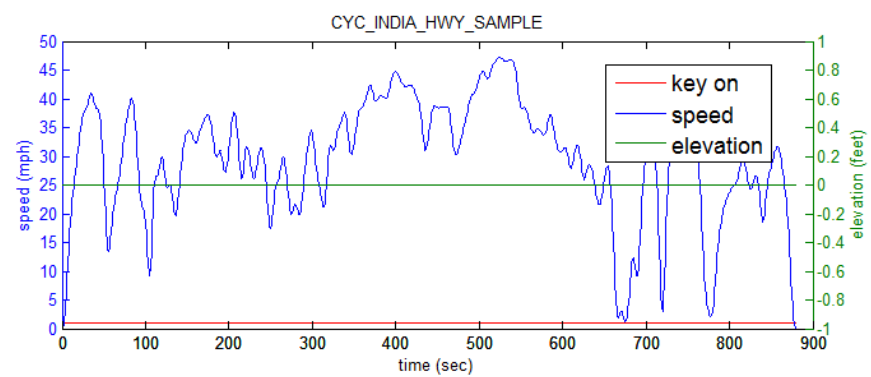

Graph 2: Indian highway drive cycle

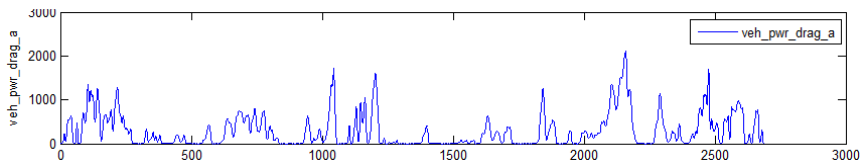

Graph 3: Power for aerodynamic/drag resistance in urban

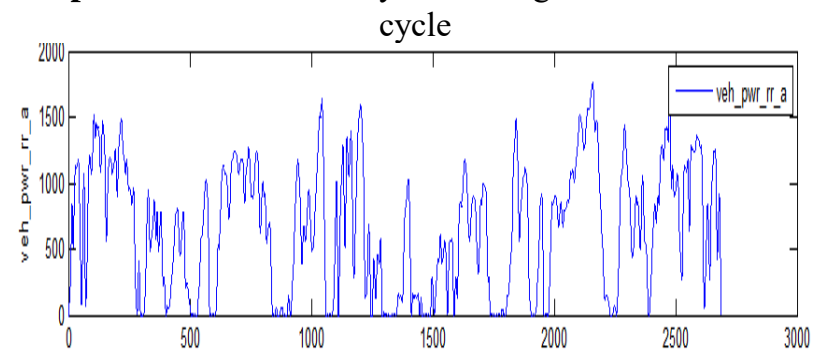

Graph 4: Power for rolling resistance in urban cycle

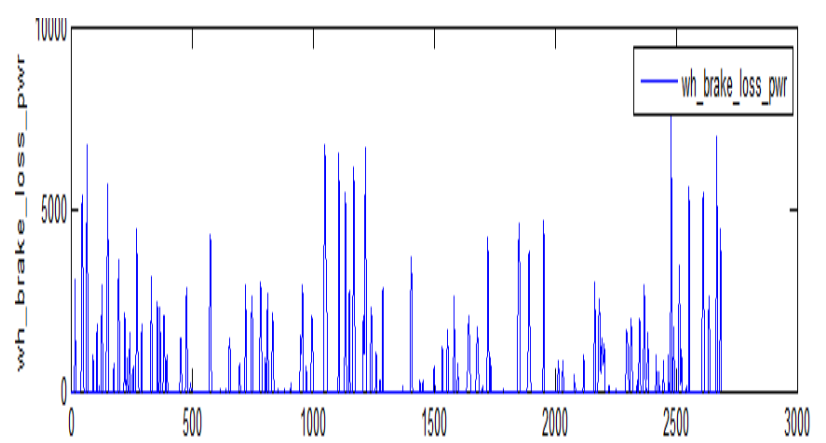

Graph 5: Power for braking resistance in urban cycle

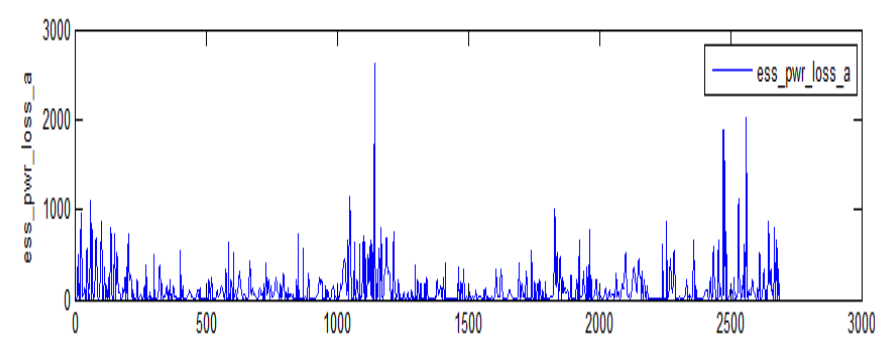

Graph.6 Power loss in energy storage in urban cycle

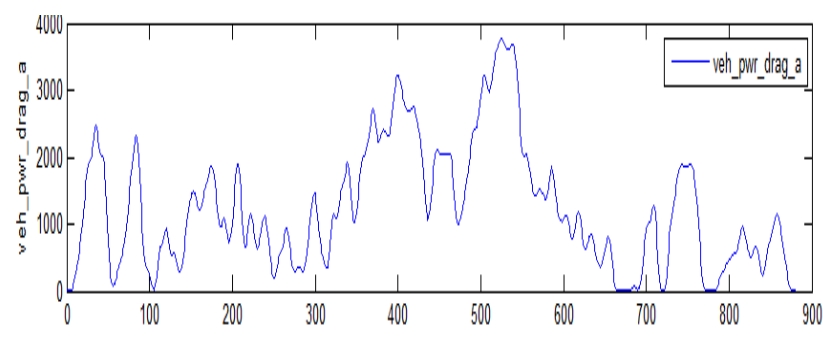

Graph 7: Power for aerodynamic/drag resistance in highway cycle

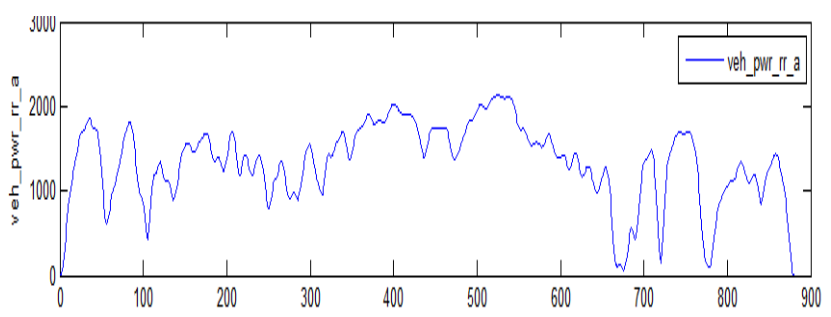

Graph 8: Power for rolling resistance in highway cycle

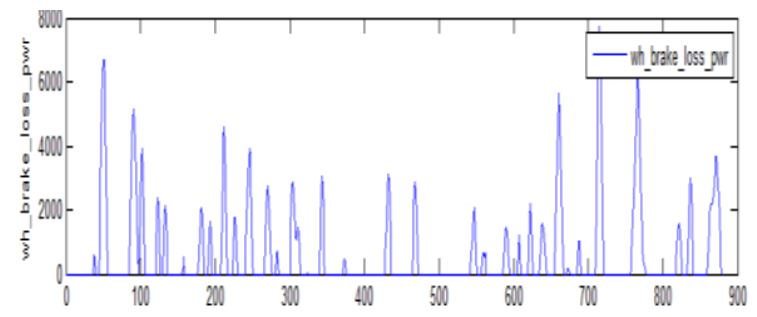

Graph 9: Power for braking resistance in highway cycle

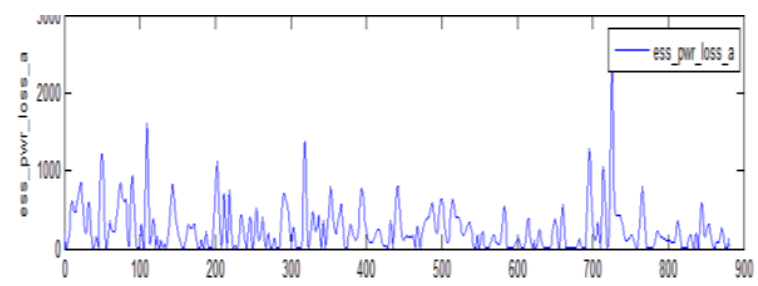

Graph 10: Power loss in energy storage in highway cycle

These graphs illustrate the power required to vehicle for overcoming various resistances in Indian urban and highway cycle.

From above calculations the energy usage and losses found out and are shown below

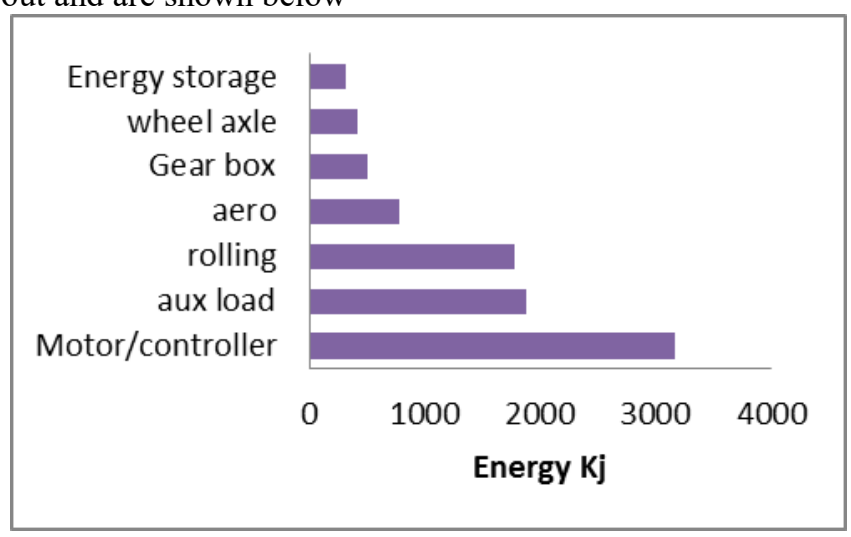

Graph 11: Power mode energy usage for Indian urban cycle 


\section{International Journal of Science and Research (IJSR) \\ ISSN (Online): 2319-7064}

Index Copernicus Value (2013): 6.14 | Impact Factor (2014): 5.611

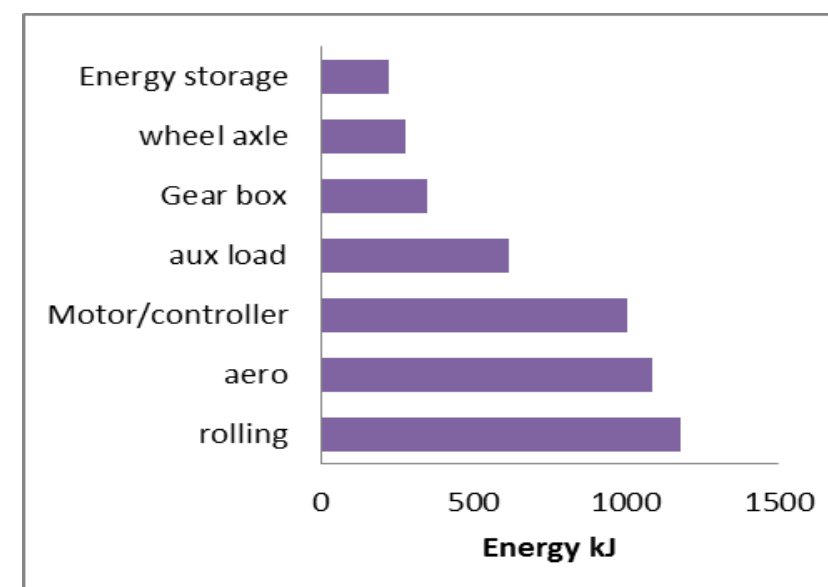

Graph 12: Power mode energy usage for Indian highway cycle

The energy and power balance are derived for electric vehicle. The effect of physical parameters calculated with the help of software and it is as per the prognosis developed earlier that the energy storage losses are far lower than the conventional vehicles. ${ }^{[18]}$

Comparison of electrical vehicle in Indian urban and Indian highway cycle

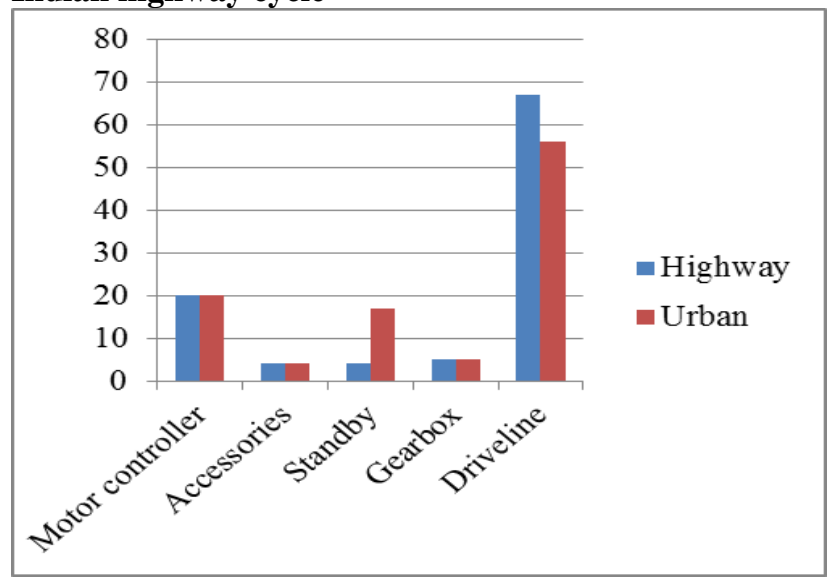

Graph 13: Percentage energy utilization comparison of electrical vehicle for Indian highway and urban cycle

From the computations the comparison of the Indian highway drive cycle and Indian urban drive cycle has been made to understand the percentage energy utilization of the conventional vehicle. It is noted that the motor, accessories and standby losses if put together the urban cycle has more the losses as 20,2,17 percentage respectively than that of highway cycle which has losses 20,2,4 respectively. The urban conditions have more standby losses than highway cycle.

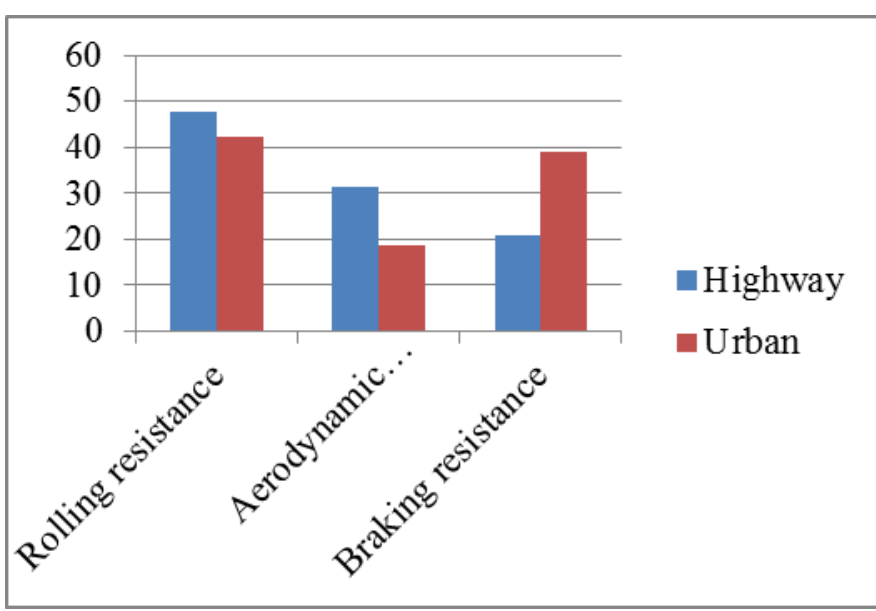

Graph 14: Percentage losses n driveline for various resistances for Indian Highway and Urban conditions

The rolling resistance energy losses are 47.7 and 42.3 percentage of driveline energy in highway and urban cycle respectively. The aerodynamic resistance energy losses are 31.4 and 18.6 percentage of driveline energy in highway and urban cycle respectively. The braking resistance energy losses are 20.9 and 39.1 percentage of driveline energy in highway and urban cycle respectively.

\section{Conclusions}

The modeling of energy balance of electric vehicle in motion is done by considering effect of various components. The results obtained by simulating the process parameters for urban and highway road conditions as per Indian urban and highway cycle with the help of ADVISOR software.

The motion of the electrical vehicle resolved as energy storage, motor/controller, gearbox, wheel axle, auxiliary load and road loads-rolling and aerodynamic resistance. The electric vehicles have less energy loss through the energy storage and motor controller than the losses in engines of IC engine vehicles. Hence there is energy conservation with respect to conventional vehicles.

It is also noted that the effect of the road loads are varied as the driving cycle changes. In highway condition significant losses are due to the rolling resistance while in urban conditions they are a smaller amount.

Thus energy conservation can be achieved by reduction in rolling resistance, the reduction of aerodynamics resistance by better shape and reduction of vehicle frontal area result in decline in power loss due to air resistance hence results in increase in efficiency.

\section{References}

[1] Thomas D. Gillespie (1992). Fundamentals of Vehicle Dynamics. Warrendale, PA 15096-0001 USA: SAE International. p1-495.

[2] Bureau of Energy Efficiency. General Aspect of Energy Management and Energy Audit. p1-23

[3] James Larminie, John Lowry (2003). Electric Vehicle Technology Explained. Antony Rowe Ltd, 
Chippenham, Wiltshire: John Wiley \& Sons Ltd. p183236.

[4] Ehsani, Modern Electric, Hybrid Electric and Fuel Cell Vehicles: Fundamentals, Theory and Design, CRC Press, 2005

[5] Richard Stone and Jeffrey K. Ball (2004). Automotive Engineering Fundamentals. Warrendale, PA 150960001 USA: SAE International. P435-491.

[6] J.Y.Wong (2001). Theory of ground vehicles. 3rd ed. Newyork: John Wiley \& Song. p203-334.

[7] Robert Bosch (2002). Bosch Electronic Automotive Handbook. $1^{\text {st }}$ Edition. p1-1301.

[8] Reza N. Jazar (2008). Vehicle Dynamics Theory and Application. Riverdale, NY: Springer. p39-209.

[9] Jan Danko et.al. (2010). Energy analysis of hybrid power source during vehicle in motion. Slovak University of technology. 3 (1), p1-6.

[10] Zdzislaw Juda. (2009). Range and acceleration analyze of an electric driven city car with advanced energy storage. Journal of KONES Powertrain and Transport. $16(2), \mathrm{p} 1-8$.

[11] G.Frydrychowicz-Jastrzębska, E. Perez Gomez. (2010).Computer simulation of power balance of a solar vehicle depending on its parameters and outside factors. Universidad de Politecnica de Cartagena 30202 Cartagena, Spain. p1-6

[12] Max Ahman. (2001). Primary energy efficiency of alternative powertrains in vehicles. Pergamon ELSEVIER . 26, p983-989.

[13] A. Irimescu, L. Mihon And G. Pãdure (2011). Automotive Transmission Efficiency measurement using a Chassis dynamometer. International Journal of Automotive Technology. 12 , p555-559.

[14] Tires and Passenger vehicle fuel economy.(2006) Transportation research board special report.p63-65.

[15] James D. Halderman (2012). Automotive Technology Principles,Diagnosis and Service. 4th ed. New Jersey: PEARSON. p1-1665.

[16] Eugene A. Avallone, Theodore Baumeister, Ali M. Sadegh (2012). Marks' Standard Handbook for mechanical engineers. 11th ed. New York: McGraw Hill. p11.1-11.128.

[17] Keith B. Wipke, Matthew R. Cuddy. Using an Advanced Vehicle Simulator (ADVISOR) to Guide Hybrid Vehicle Propulsion System Development. National Renewable Energy Laboratory, Golden, CO. p1-6

[18] Shivraj Pawar, N.N.Shinde, M.M.Wagh.(2014) Analysis of Effect of Physical Parameters on Energy Balance for Energy Conservation for Vehicle in Motion. IJETAE Volume 4, Issue 8, August 2014. P268-272.

\section{Author Profile}

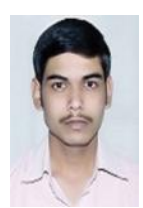

Shivraj Pawar is B.E. Mechanical Engineering M.Tech Student, Energy Technology, Department of Technology, Shivaji University, Kolhapur, Maharashtra, India. 